\title{
Patient satisfaction with skill mix in primary care: a review of the literature
}

Christine Branson Torbay Primary Care Trust, Torquay, UK, Beryl Badger Plymouth Business School, University of Plymouth, Plymouth, UK and Frank Dobbs University of Plymouth, Plymouth, UK

This literature review focuses on patient satisfaction with skill mix in primary care. This is an important, rapidly changing, topic as the range of health professionals working alongside GPs increases and the roles of staff change. The review is intended to assist primary care organizations in developing skill mixes that meet patients' preferences and needs.

A number of characteristics that influence the type of services that patients want were discovered. Older people and those from ethnic minorities want a 'traditional', GP-led service. Access is important to younger people and those in full-time work. Those from lower socio-economic groups value nurses, but have found the increasingly complex organization of services a problem. There are different levels of knowledge and expectations about health services and information on the skills and knowledge of professionals, what they do and the links between them, needs to be available.

A number of aspects of care are important to patients. Patients liked nurses as they were good communicators, formed good therapeutic relationships, gave information on illnesses and spent more time. The location of services is important and patients liked services provided in the home or community. Continuity of care is key, but has been presented as old fashioned and reorganizations may have reduced continuity; skill mix could be viewed as forming a barrier between doctor and patient, but personal lists and teams where practices are divided into smaller units with shared support may help. The competence of health professionals is clearly vital and patients considered nurses competent, although they had concerns about nurses and pharmacists taking on some new roles.

The literature focuses on patients' views about doctors and nurses, although they also want a wider range of services and professionals available in primary care: occupational therapy, link workers, $C A B$ advisers, pharmacist advice and mental health workers. Despite being satisfied with nurses, some patients still wanted to see a doctor next time or felt that a doctor should be available. GPs can help build awareness and confidence in patients about the roles and contribution of the team.

Key words: literature review; patient satisfaction; primary care; skill mix

\section{Introduction}

This literature review focuses on patient satisfaction with skill mix in primary care. Research into the topic is important as there is rapid and substantial change as a greater range of health pro-

Address for correspondence: Christine Branson, Torbay Primary Care Trust, Rainbow House, Avenue Road, Torquay TQ2 5LS, UK. Email: christine.branson@torbay-pct.nhs.uk fessionals' work alongside GPs and the roles of practice-based staff change. Key drivers are the increasing demand and cost of care, a shift from hospital-based to community services and difficulties with the recruitment and retention of general practitioners. Despite the importance of the topic, there is little research available and that which does exist is scattered across the specialist literature of different groups and tends to focus on a single aspect of skill mix, rather than the complexity of delegation and diversification. 
In order to determine patient satisfaction with skill mix, the review first considers the characteristics of patients that influence their satisfaction with health services. Then studies which have been undertaken on patient satisfaction with primary care and particular professionals working in primary care are considered, which can, when viewed together start to give an indication of aspects of skill mix, which may be satisfactory or not to patients. The results of the review are intended to assist primary care teams and policy makers in developing skill mixes that meet patients' preferences and needs. A pictorial summary of the issues arising from the literature review is shown in Figure 1.

\section{Methodology: search terms and strategy}

The following electronic clinical databases were searched between October and December 2000:

- HMIC (Health Management Consortium database combining the Department of Health, King's Fund and Nuffield Institute's HELMIS)

- Medline

- Cinahl

- $\mathrm{RCN}$ journals database

- BNI (British nursing index)

- Embase

- PsychInfo

- Assia

- Amed

The following search terms were used:

- Skill mix

- Primary care

- General practice

- Patient satisfaction

- Patient attitudes

- Patient views

The Boolean operator 'and' and 'wildcard' symbols were used in the search.

'Skill mix' in this case focuses on the mix of disciplinary groups in the delivery of a service. It also encapsulates the definition offered in both skill-mix bibliographies (Halliwell et al., 1998; Sergison et al., 1998), focusing on delegation and diversification. Delegation is where tasks are transferred from expensive, highly qualified pro- fessionals, such as GPs and senior nurses, to cheaper, less highly qualified staff, such as junior nurses and nurse assistants. Diversification is where additional services or professionals are added to the practice meet health needs and/or replace services provided in hospital and other settings.

'Primary care', in this context, means GPs and the clinical teams of directly employed staff nurse practitioners, practice nurses and nurse/health care assistants. The roles of district nursing, health visitors, mental health workers and community pharmacists are considered less often as the literature does not focus on them quite so much and they are employed by other organizations. However, they do still have a part to play.

'Patient' is taken to mean anyone registered with a general practice, whether they are regular users of the service or not. 'Satisfaction' is taken to mean the extent to which a patient's expectations or needs are adequately met by the service offered.

As expected, a large number of references was generated. An assessment of the relevance of the studies was undertaken by one reviewer (CB) on the basis of the title, abstract and key words. Potentially relevant articles were obtained in full, if possible. In view of the difficulty that the search terms may exclude articles' relevance to the topic, the reference lists of all articles were searched.

The two bibliographies on skill mix in primary care from the National Primary Care Research and Development Centre (Halliwell et al., 1998; Sergison et al., 1998) were also used; full text articles of abstracts including the key words 'patient satisfaction' or 'patient views' were gained, where possible.

All types of studies and participants were included in the literature review. The main limitation to whether a study was included in the review was the ease with which it could be accessed by the reviewer; generally, studies reported in journals from abroad proved difficult to get hold of.

Details of each study (topic researched, design, number of participants, data yield, key findings, setting and limitations/weaknesses) were entered on to a database constructed using the Excel spreadsheet package. Quality assessment and relevance to the topic area was carried out by one reviewer (CB); all studies were scored using the following principles: 
Satisficers
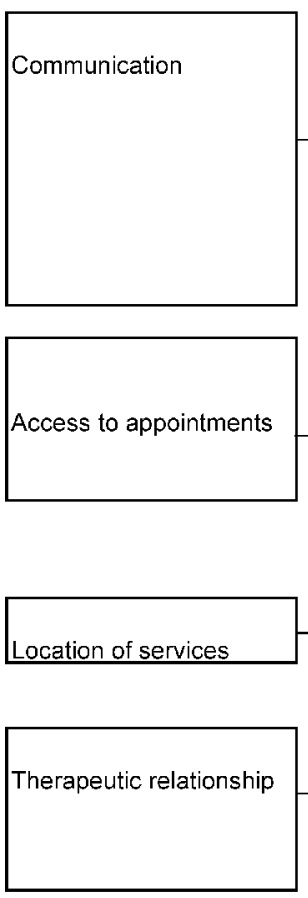

$\sqrt{2}+2$

ength of consultation

Information giving



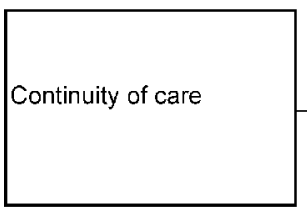

\begin{tabular}{|l|l|}
\hline $\begin{array}{l}\text { Development of skill mix can adversley } \\
\text { affect continuity and personal care }\end{array}$ \\
\hline $\begin{array}{l}\text { More professionals in skill mix leads to } \\
\text { larger practice teams which affects } \\
\text { personal care and continuity }\end{array}$ \\
\hline
\end{tabular}

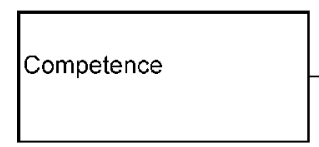

Skill mix implications

Phenomena

Greater use of nurses who are easier to talk to

Greater use of GP specialists who are popular as hospital doctors are less easy to communicate with

Ability to see different professionals means that patient who prefer shared or directive styles of consulting can see a professional who does this

\begin{tabular}{|l|l|}
$\begin{array}{l}\text { More staff involved in delivery of care } \\
\text { means greater availability of } \\
\text { appointments }\end{array}$ & Age \\
\hline $\begin{array}{l}\text { Delegation from GPs to others frees up } \\
\text { GP appointments }\end{array}$ & \\
\hline & Employment status \\
\hline & Gender \\
\hline & Expectations of NHS \\
\hline
\end{tabular}

Primary care based services popular as opposed to hospital based

Health status

Expectations of NHS

\begin{tabular}{|l|l|}
$\begin{array}{l}\text { Greater use of nurses who build good } \\
\text { relationships with patients }\end{array}$ & Social class \\
\hline $\begin{array}{l}\text { Some concern that skill mix might affect } \\
\text { building therapeutic relationships }\end{array}$ & \\
& Emplovment status \\
& Gender \\
\hline & Level of deprivation \\
\hline
\end{tabular}

Greater use of nurses who spend more time Greater use of mental health workers who can spend longer with those with psychological problems Greater use of other staff means GPs can spend longer with patients

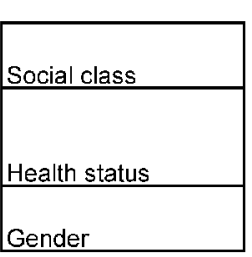

Greater use of nurses who give more information

Some prefer GPs to give advice which skill mix reduces

\section{Social class}

Age

Ethnicity

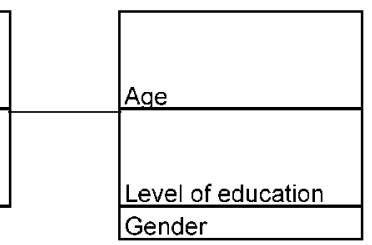

Nurses taking on new tasks might be concerning to patients

Pharmacists taking on new tasks might

be concerning to patients
Gender

Knowledge of health services

Figure 1 Skill mix in primary care: satisficers, implications and patient phenomena 
- Grade A, excellent source;

- Grade B, pertinent information, but very limited;

- Grade C, interesting but subjective or of questionable reliability;

- Grade D, not pertinent.

Those studies that scored lower grades, that is $\mathrm{C}$ and $\mathrm{D}$, were either excluded from the final review, or mentioned only in support of other higher graded studies. Seventy-five articles were uncovered by the search strategy, and 15 were excluded.

Prospective searching of core journals in this area continues; the journals that are searched are:

British Medical Journal

British Journal of General Practice

Family Practice

Health and Social Care in the Community

Journal of Advanced Nursing

Nursing Standard

Primary Health Care Research and Development

\section{Results}

\section{Methodological issues}

The majority of research into patient satisfaction with primary care has adopted a quantitative approach characterized by large samples, statistical data yield and a tendency for questionnaires to be used. Of 52 primary research articles collected, 30 were of a quantitative design. It has been noted that quantitative measures lack discriminatory ability (Bond and Thomas, 1992) and the reductionism and standardization involved in quantitative methods can remove much of the meaning and this is evidenced by the high levels of patient satisfaction recorded in the majority of studies (Lewis, 1994; Williams, 1994). The implication is that the design and use of questionnaires is very important, as poorly designed and executed questionnaires can act as censorship, giving misleading results and limiting the opportunity for patients to express concerns (Lewis, 1994; Williams, 1994). Questionnaires also tend to suffer from low response rates, particularly amongst younger people, those in poorer areas and those unable to read or write (Cohen et al., 1996; Lewis, 1994); this can lead to nonresponse bias.

Qualitative methods have been identified as allowing a more critical slant to come through in patient satisfaction studies (Williams, 1994). However, few of the articles reviewed used a qualitative methodology; of the 52 primary research articles, only six used a qualitative approach. It was, however, slightly more common for triangulation of methodologies: developing questionnaires from open-ended interviews with patients or focus group work, which was pursued in 16 of the articles. This suggests that further research is required using qualitative methodologies.

There are other issues of relevance to a literature review of this topic area. Primary care teams do tend to be quite different from each other, largely due to the independent contractor status of the GP and the nature of the population that they serve; many of the studies therefore warned that the results might not be generalized to other practices. Different meanings have been found for 'patient satisfaction' (Bond and Thomas, 1992; Lewis, 1994; Mahon, 1996; Mangen and Griffith, 1982) and the lack of definition and discriminatory ability might lead to the high levels of satisfaction reported in many studies (Bond and Thomas, 1992).

\section{Influences on patient satisfaction}

Patient satisfaction is affected by knowledge of health services (Bond and Thomas, 1992; Mangen and Griffith, 1982; NHS Executive, 1999). Expectations of services have also be found to be influenced by previous experiences of health care. Knowledge and experience of the changing roles of different health professionals, such as doctors and nurses (Bond and Thomas, 1992) can therefore affect satisfaction and this should be an important consideration in implementing skill mix changes. The literature shows that patients are less sure of the role of the nurse than the doctor (Phillips and Brooks, 1998; Staniszewska and Ahmed, 1998) and to explore further patients' perceptions and knowledge of these roles a study has been undertaken on a nurse-led pilot, where the nurse employs the GP (Chapple et al., 2000). Patients' perceptions of the role of the nurse were influenced by a number of sources, including letters from the health authority, comments from receptionists, newspaper articles, information leaflets, their own and other patients' experiences and previous contact with a nurse practitioner. There is clearly a need for patient information on the skills and knowledge of 
different health and social care professionals, what they do and the links between them (Forum on Teamworking in Primary Care, 2000). It may also be the case that people's perceptions of doctors and nurses taking on new roles may change when they have actually experienced this.

Age is the most frequently cited influence on patient satisfaction, with 23 studies in this area. There is a tendency for older people to be more satisfied (Department of Health, 2000; Grogan et al., 1995; Howie et al., 1999; Hull and Hull, 1984; Jenkins-Clarke et al., 1997; Larsson, 1999; Treadway, 1983) although not all show a link (Baker, 1990; Kaim-Caudle and Marsh, 1975). It is also difficult to determine the preferences of 'young' and 'old' people, as people aged 16 and under were excluded from most of the review studies and definitions of younger and older people were seldom given or differed. The link between increasing age and satisfaction is complex (Baker and Streatfield, 1995) and may be because some older patients can remember before the NHS existed (Larsson, 1999). It may also be because they are treated with more respect and consideration by some health professionals (Larsson, 1999; Lewis, 1994) as they feel more comfortable dealing with more passive elderly people, compared with consumerist younger people (Williams, 1994). Their views will also be determined by the services they receive (Baker and Streatfield, 1995) and studies show that older patients seem to receive better services (Baker, 1990; Department of Health, 2000; Freeman and Richards, 1993; Howie et al., 1999; Kaim-Caudle and Marsh, 1975; O'Reilly et al., 2001). It is also important to remember though that older people do tend to have more complex health problems and higher levels of need (Larsson, 1999). It may be that skill mix divides the young and the old, providing more satisfactory services for younger people. As older people want a more 'traditional' service (Baker and Streatfield, 1995; Jenkins-Clarke et al., 1997; Lewis, 1994; Williamson, 1995) they may be more resistant to skill mix (Forum for Teamworking in Primary Healthcare, 2000). But, as access issues are most important to younger people, particularly those that work (Department of Health, 2000; Forum for Teamworking in Primary Healthcare, 2000), skill mix involving nurse-led services at weekends or early in the morning or later at night (Dobson, 1999) may meet their needs better. Chapple et al.,
(2001) also found that younger people would be more likely to use a NHS walk-in centre.

Health status has been shown to influence services required and satisfaction, as evidenced in 13 articles. A distinction can be drawn between patients presenting with chronic or psychological problems and, acute or physical problems. Those with chronic or psychological problems prefer a shared consulting style, characterized by good communication and patient centred consultations (Savage and Armstrong, 1990). However, other studies have shown that they want a more directive style, to get reassurance or to avoid responsibility for a poor outcome (Little et al., 2001; McKinstry, 2000). Continuity does seem to be important for those with chronic problems (Freeman and Hjortdahl, 1997), whereas those with acute problems are less bothered who they see (Taylor, 2001) and they prefer a directive style of consultation (McKinstry, 2000; Savage and Armstrong, 1990). This is supported by Sibbald et al. (2001) who found that those with urgent health care problems would be more likely to use a NHS walk-in centre as they did not mind who they saw.

Although it has been stated that there are few class differences in patient satisfaction with primary care (Department of Health, 2000; KaimCaudle and Marsh, 1975), 13 studies were found showing socio-economic preferences relevant to skill mix developments. Those from nonmanual social classes prefer a shared consultation style (McKinstry, 2000), which is likely to be connected to their view that the GP does not always know best (Department of Health, 2000). Working class people have been found to value nurses most, possibly because they find them easier to talk to (Bowling, 1981). However, increasingly complex organization of health care can inhibit the participation of this group (Brearley, 1990). Those in paid work or full-time education are least satisfied with access to primary care (Department of Health, 2000) and tend to use the community pharmacy as a 'first point of call' instead (Hassell et al., 1997).

There is no clear link in the 12 studies found on gender and satisfaction. Some studies suggest that women are less satisfied (Department of Health, 2000; Larsson, 1999) and others that they were more satisfied (Grogan et al., 1995)! Women do use health services more often than men (Department of Health, 2000) so satisfaction may be linked to how well they feel their expectations 
were met at their last visit (Thorsen et al., 2001). Similarly, men have been found to be both satisfied with consultation time (Baker, 1990; Department of Health, 2000) and dissatisfied (Hull and Hull, 1984).

There has been very little research involving patients from an ethnic minority, particularly those who may have a limited understanding of English; only five studies were found. Lower levels of satisfaction with primary care, organized around the GP practice, have been found (Department of Health, 2000) and Sibbald etal. (2001) found that as a result of this, people from ethnic minorities would be more likely to use a NHS walk-in centre. They also feel that it is important for the GP to carry out basic tasks, such as taking blood and giving injections (Lewis, 1994) which obviously has implications for skill mix, as delegation of these procedures to nurses is common.

The literature on what influences satisfaction appears to have a recurring theme of the impact of expectations and knowledge of health care, regardless of other characteristics. Those who use the service more are more knowledgeable about it, and can decide whether it meets their expectations and from this how satisfied they are. Age, health status and socio-economic status appear show the most firm evidence for determining levels of satisfaction. The literature is either scarce or contradictory for gender and ethnicity, suggesting that further research is required in these areas.

\section{What matters to patients}

Communication is the most frequently mentioned satisfier, mentioned in 26 studies on satisfaction. Patients require good communication with a health professional and they also expect health professionals to talk to each other (Ovretveit, 1997). A number of studies indicate that nurses are viewed by patients as good communicators, sometimes better than doctors (Mangen and Griffith, 1982; Paykel et al., 1982; Paxton and Heaney, 1997; Venning et al., 2000). However, this may only be applicable to primary care as hospital studies have shown that patients felt that nurses' communication was poor (McColl et al., 1996; Staniszewska and Ahmed, 1998). This is supported by work on doctors' communication which found that GPs are viewed as better communicators than hospital doctors (Murphy et al., 1992; Williams, 1994). This may be due to the setting; Rapport and
Maggs (1997) found that patients felt more able to voice their concerns to district nurses as they saw them in their homes and they felt more comfortable in this setting.

Patients are concerned about the amount of time that professionals spend with them, and 22 studies were found in this area. High levels of satisfaction have been reported with nurses (Kinnersley et al., 2000; Mangen and Griffith, 1982; Paykel et al., 1982; Poulton, 1995; Shum et al., 2000; Venning et al., 2000). The NHS survey also found that people were satisfied with GPs (Department of Health, 2000) although patients probably expect consultations with general practitioners to be shorter (Poulton, 1996). Regardless of professionals, there is a quality argument for longer consultations (Jenkins-Clarke et al., 1997; Morrell et al., 1986; Venning et al., 2000) and to achieve this, reductions in home visiting and delegation through skill mix have been suggested (Hull and Hull, 1984; Forum for Teamworking in Primary Healthcare, 2000).

Continuity of care has been shown to be important to patients and was mentioned in 21 studies. It has been found to be particularly important for older patients, females and those from disadvantaged communities (Chapple et al., 2000; Jenkins-Clarke et al., 1997; Ross and Tisser, 1997). But, despite its importance to patients, continuity can be seen as old fashioned and in opposition to the development of modern primary care (Guthrie and Wyke, 2000) and concerns have been expressed that NHS reorganizations seem to reduce personal continuity (Baker and Streatfield, 1995; Guthrie and Wyke, 2000; Hull and Hull, 1984; Neuberger, 1998; Williamson, 1995). Further, continuity and satisfaction may decrease as the size of practices increases (Audit Commission, 2001; Baker, 1990; Baker and Streatfield, 1995; Howie et al., 1999) and skill mix could also affect continuity and be viewed as forming a barrier between doctor and patient (Bowling, 1981). However, the study by Jenkins-Clarke et al. (1997) found no clear relationship between practice size and continuity. Proposals have been put forward to help achieve personal continuity where larger practices have personal lists and are divided into a number of smaller, individual patient-centred teams with shared administrative and support functions (Baker and Streatfield, 1995; Forum on Teamworking in Primary Healthcare, 2000); 
Guthrie and Wyke (2000) identified primary care trusts as a mechanism to do this.

The competence of health professionals is clearly important to patients and is discussed in 20 studies. Some have suggested that patients cannot assess competence (Brearley, 1990; Mangen and Griffith, 1982), although others advise that although they may judge 'technical ability' differently from professionals this does not mean that one is correct or better (Bond and Thomas, 1992). Patients have judged the competence of nurses favourably (Department of Health, 2000; Paykel et al., 1982; Poulton, 1995; 1996; Shum et al., 2000), although there are concerns about nurses' competence in new roles (Paxton and Heaney, 1997; Wiles, 1997).

It is important for patients to receive adequate information as shown in 18 studies. Again, patients have expressed high levels of satisfaction with the amount of information that nurses provide (Kinnersley et al., 2000; Shum et al., 2000). However, the studies on patient satisfaction with GPs show contradictory results: some showed patients were satisfied (Department of Health, 2000; KaimCaudle and Marsh, 1975), whereas others showed that patients would have liked more information (Baker, 1990; Brearley, 1990; Grogan et al., 1995).

Depth of relationship has been identified as a key attribute of patient satisfaction with primary care, identified in 12 studies. Some patients are most satisfied with their relationship with nurses (Paykel etal., 1982; Shum et al., 2000) and in some studies, patients seemed more satisfied with the relationship with the nurse than with the GP (Shum et al., 2000). However, another study showed poor depth of relationship when patients were seeing the nurse for the first time (Poulton, 1995).

The location of services is important and skill mix has lead to some services being provided in the home or community, when previously the patient had to travel to a hospital or other location; there are 12 studies in this area. Accessibility, reduced waiting times, reduced travelling costs and depth of relationship have all been found to be advantages to patients (Diabetes Integrated Care Evaluation Team, 1994; Forum for Teamworking in Primary Healthcare, 2000; Galvin et al., 2000; Gillam et al., 1995; Murphy et al., 1992; Wiles, 1997). However, some disadvantages have been identified as well - notably concerns from patients about quality and competency (Diabetes Integrated Care Evaluation Team, 1994; Hindler et al., 1995; Wiles, 1997).

The literature on what matters to patients seems to focus on communication, time spent with professionals, continuity of care, competence and information giving. It suggests that nurses are seen as good communicators, who spend time with patients and give them adequate information on their illnesses. However, there are some concerns about competence and the effect on continuity of introducing other professionals into the care process. Depth of relationship with professionals, and satisfaction with the location of services, is less frequently reported although relationships with nurses are again viewed positively, as were a greater range of services from practices.

\section{Professionals involved in skill mix in primary care}

The literature tends to focus on the patient views about doctors and nurses in primary care, with 38 studies in this area. However, patients also want a wide range of services and professionals to be available at the practice including physiotherapy, podiatry, osteopathy, consultant sessions, housing advice, social services and benefits advice (Neuberger, 1998). Patient satisfaction with these services, if they even exist, is much less frequently reported and suggests that further research would be required in this area.

Patient satisfaction with nurses in primary care is high because they are felt to be easy to talk to, professional, spend more time, give good advice and information and are good at dealing with children and parents (BBC News, 2000; Bhopal, 1994; Brown and Grimes, 1995; Department of Health, 2000; Dolan et al., 1997; Drury etal., 1988; Jenkins-Clarke etal., 1997; Kinnersley et al., 2000; Poulton, 1995; 1996; Salisbury and Tettershall, 1988; Shum et al., 2000). However, patients feel that there are limits to the nurse role with patients still preferring to see the doctor at the next visit for a minor illness (Kinnersley et al., 2000; Shum et al., 2000) and female patients preferring to see a female GP rather than a nurse (Phillips and Brooks, 1998). However, Murray and Paxton (1993) found that apart from an initial consultation for oral contraception, patients would prefer to see the nurse for family planning. Patients seem to value access to the nurse, but she is seen as an 
assistant to the GP which suggests a lack of understanding of their potential (Phillips and Brooks, 1998; Wiles, 1997; Williamson, 1995). GPs can help to raise awareness and confidence in their patients about nurses (Jenkins-Clarke et al., 1996; Wiles, 1997; Williamson, 1995).

There are few examples of other staff working with primary care teams and a measure of patient satisfaction with these services. Eight studies were found on primary care-based mental health services which were popular with patients who preferred talking therapy to medication (Goldberg et al., 1996; Greener, 2000; Mangen and Griffith, 1982; Paykel et al., 1982; Priest et al., 1996; Simpson et al., 2000; Spiers and Jewell, 1995); a study on the management of depression showed that collaborative working arrangements, either between GPs and psychiatrists or psychiatrists and psychologists, were most popular with patients (Katon et al., 1997). Only four studies were found on patient satisfaction with community nurses which showed satisfaction with care, relationship and time with district nurses, but lower levels of satisfaction with health visitors (Poulton, 1996; Rapport and Maggs, 1997). However, another health visitor study on their role in managing acute minor illnesses found that patients reported higher levels of satisfaction than those seeing the GP or practice nurse (Pritchard and Kendrick, 2001); this may be because the numbers seen by health visitors were small and they focused on children under 5. Other services which appeared only once in the literature were nurse and occupational therapist-led clinics (NHS Executive, 2000), link workers (Gillam and Levenson, 1999) and CAB advisers (Galvin et al., 2000); although satisfaction was high, more studies would be needed to provide an evidence base.

The literature focuses largely on views of doctors and nurses in primary care, with few studies considering other services. Nurses are viewed positively, although there are some concerns about limits to their role. Of the other professionals reported, primary care mental health services are popular with patients and there is some satisfaction with community nurses, although more research is needed.

\section{Conclusions}

The information on what influences patient satisfaction, what patients want and patient satisfaction with professionals in primary care can assist in designing skill mix for different populations depending on their preferences. This information will be useful to practices considering their own skill mix developments and primary care organizations engaged in primary care development.

The studies in this area were mostly quantitative, characterized by large samples, statistical data yield and a tendency for questionnaires to be used. The literature on what influences satisfaction appears to have a recurring theme of the impact of expectations and knowledge of health care, regardless of other characteristics. Age, health status and socio-economic status appear to show the most firm evidence for determining levels of satisfaction. The literature is either scarce or contradictory for gender and ethnicity, suggesting that further research is required in these areas. The literature on what matters to patients focuses on communication, time spent with professionals, continuity of care, competence and information giving. It suggests that nurses are good communicators, who spend time with patients and give them adequate information on their illnesses. However, there are some concerns about competence and continuity. Regarding professionals, the literature focuses on doctors and nurses with few studies considering other services. Nurses are viewed positively, although there are some concerns about limits to their role.

The literature review has highlighted areas where little research has been undertaken. There is a need for further research to consider patient views on a much wider range of services in primary care, such as physiotherapy, podiatry, osteopathy, consultant sessions, housing, social services and welfare benefits. Despite a wealth of research on practice nurses and nurse practitioners involvement in skill mix, there is little research available on how patients feel about the involvement of 'attached' nurses, such as district nurses and health visitors in practice skill mix developments. There is also the potential for more studies on the satisfaction of the under-16s and those from ethnic minorities and, further studies on the effect of gender.

\section{References}

Audit Commission 2001: Specification for a project on general practice. London: Audit Commission. 
Baker, R. 1990: Development of a questionnaire to assess patients' satisfaction with consultations in general practice. British Journal of General Practice 40, 487-90.

Baker, R. and Streatfield, J. 1995: What type of general practice do patients prefer? Exploration of practice characteristics influencing patient satisfaction. British Journal of General Practice 45, 654-59.

BBC News. 2000: Patients prefer nurses, http://www. news.bbc.co.uk/hi/english/health/newsid_711000/711868.stm, retrieved October, 2000.

Bhopal, R. 1994: Skill mix in primary care. British Medical Journal 309, 195-96.

Bond, S. and Thomas, L.H. 1992: Measuring patient satisfaction with nursing care. Journal of Advanced Nursing 17, 52-63.

Bowling, A. 1981: Delegation in general practice. A study of doctors and nurses. London: Tavistock Publications Ltd.

Brearley, S. 1990: Patient participation: the literature. Middlesex: Scutair Press.

Brown, S. and Grimes, D.E. 1995: A meta-analysis of nurse practitioners and nurse midwives in primary care. Nursing Research $44,322-39$.

Chambers, N.L. 1998: Nurse practitioners in primary care. Oxford: Radcliffe Medical Press.

Chapple, A., Rogers, A., Macdonald, W. and Sergison, M. 2000: Patients' perceptions of changing professional boundaries and the future of 'nurse-led' services. Primary Health Care Research and Development 1, 51-59.

Chapple, A., Sibbald, B. and Rogers, A. 2001: Citizens' expectations and likely use of a NHS walk-in centre: results of a survey and qualitative methods of research. Health Expectations 4, 38-47.

Cohen, G., Forbes, J. and Garraway, M. 1996: Can different patient satisfaction survey methods yield consistent results? Comparison of three surveys. British Medical Journal 313, $841-44$.

Department of Health. 2000: The national survey of NHS patients general practice: 1998. http://www.doh.gov.uk/public/ nhssurveygp.htm, retrieved 9 December, 2002.

Diabetes Integrated Care Evaluation Team. 1994: Integrated care for diabetes: clinical psychological and economic evaluation. British Medical Journal 308, 1208-12.

Dobson, R. 1999: Patients satisfied with nurse run practices. British Medical Journal 319, 728.

Dolan, B., Dale, J. and Morley, V. 1997: Nurse practitioners: the role in A\&E and primary care. Nursing Standard 11, 33-37.

Drury, M., Greenfield, S., Stilwell, B. and Hull, F.M. 1988: A nurse practitioner in general practice: patient perceptions and expectations. Journal of the Royal College of General Practitioners 38, 503-505.

Fall, M., Walters, S., Read, S., Deverill, M., Lutman, M., Milner, P. and Rodgers, R. 1997: An evaluation of a nurseled ear care service in primary care: benefits and costs. British Journal of General Practice 47, 699-703.

Forum on Teamworking in Primary Healthcare. 2000: Teamworking in primary healthcare realising shared aims in patient care, final report. London: Royal Pharmaceutical Society of Great Britain and the British Medical Association.

Freeman, G. and Hjortdahl, P. 1997: What future for continuity of care in general practice? British Medical Journal 314, 1870.

Freeman, G.K. and Richards, S.C. 1993: Is personal continuity of care compatible with free choice of doctor? Patients' views on seeing the same doctor. British Journal of General Practice 43, 493-97.

Galvin, K., Sharples, A. and Jackson, D. 2000: Citizens Advice Bureaux in general practice: an illuminative evaluation. Health and Social Care in the Community 8, 277-82.

Gillam, S.J., Ball, M., Prasad, M., Dunne, H., Cohen, S. and Vafidis, G. 1995: Investigation of benefits and costs of an ophthalmic outreach clinic in general practice. British Journal of General Practice 45, 649-52.

Gillam, S. and Levenson, R. 1999: Editorial - Linkworkers in primary care. An untapped resource. British Medical Journal $319,1215$.

Goldberg, D., Jackson, G., Gater, R., Campbell, M. and Jennett, N. 1996: The treatment of common mental disorders by a community team based in primary care: a cost-effectiveness study. Psychological Medicine 26, 487-92.

Greener, M. 2000: Patient choice stokes demand for primary care counselling services. Primary Care Report December, 12-15.

Grogan, S., Conner, M., Wilits, D. and Norman, P. 1995: Development of a questionnaire to measure patients' satisfaction with general practitioners' services. British Journal of General Practice 45, 525-29.

Guthrie, B. and Wyke, S. 2000: Does continuity in general practice really matter? British Medical Journal 321, 736-37.

Halliwell, S., Sibbald, B. and Rose, S. 1998: A bibliography of skill mix in primary care, the sequel. Manchester: National Primary Care Research and Development Centre.

Hassell, K., Rogers, A. and Noyce, P. 2000: Community pharmacy as a primary health care resource: a framework for understanding pharmacy utilization. Health and Social Care in the Community 8, 40-49.

Heywood, P. 2000: The changing character of service provision. Contemporary primary care the challenges of change. Buckingham: OU Press.

Hindler, C., Nazareth, I., King, M., Cohen, J., Farmer, R. and Gerada, C. 1995: Drug users' views on general practitioners. British Medical Journal 310, 302.

Hjortdahl, P. and Laerum, E. 1992: Continuity of care in general practice: effect on patient satisfaction. British Medical Journal 304, 1287-90.

Howie, J.G.R., Heaney, D.J., Maxwell, M., Walker, J.J., Freeman, G.K. and Rai, H. 1999: Quality at general practice consultations: cross sectional survey. British Medical Journal 319, 738-43.

Hull, F.M. and Hull, F.S. 1984: Time and the general practitioner: the patient's view. Journal of the Royal College of General Practitioners 34, 71-75.

Jenkins-Clarke, S., Carr-Hill, R., Dixon, P. and Pringle, M. 1997: Skill mix in primary care. A study of the interface

Primary Health Care Research and Development 2003; 4: 329-339 
between the general practitioner and other members of the primary health care team. University of York: Centre for Health Economics.

Katon, W., Von Korff, M., Lin, E., Simon, G., Walker, E., Bush, T. and Ludman, E. 1997: Collaborative management to achieve depression treatment guidelines. Journal of Clinical Psychiatry 58, 20-23.

Kaim-Caudle, P.R. and Marsh, G.N. 1975: Patient-satisfaction survey in general practice. British Medical Journal 1, 262-64.

Kinnersley, P., Anderson, E., Parry, K., Archard, L., Turton, P., Stainthorpe, A., Fraser, A., Butler, C.C. and Rogers, C. 2000: Randomized controlled trial of nurse practitioner versus general practitioner care for patients requesting 'same day' consultations in primary care. British Medical Journal 320, $1043-48$.

Larsson, B.W. 1999: Patients' views on quality of care: age effects and identification of patient profiles. Journal of Clinical Nursing 8, 693-700.

Lewis, J.R. 1994: Patients views on quality care in general practice: literature review. Social Science and Medicine 39, 655-70.

Little, P., Everitt, H., Williamson, I., Warner, G., Moore, M., Gould, C., Ferrier, K. and Payne, S. 2001: Preferences of patients for patient centred approach to consultation in primary care: observational study. British Medical Journal 322, 46872.

Mahon, P.Y. 1994: An analysis of the concept 'patient satisfaction' as it relates to contemporary nursing care. Journal of Advanced Nursing 24, 1241-48.

Mangen, S.P. and Griffith, J.H. 1982: Patient satisfaction with community psychiatric nursing: a prospective controlled study. Journal of Advanced Nursing 7, 477-82.

McColl, E., Thomas, L. and Bond, S. 1996: A study to determine patient satisfaction with nursing care. Nursing Standard 10, 34-38.

McKinstry, B. 2000: Do patients wish to be involved in decision making in the consultation? A cross sectional survey with video vignettes. British Medical Journal 321, 867-71.

Morrell, D.C., Evans, M.E., Morris, R.W. and Roland, M.O. 1986: The 'five minute' consultation: effect of time constraint on clinical content and patient satisfaction. British Medical Journal 292, 870-73.

Murphy, E., Kinmonth. A. and Marteau, T. 1992: General practice based diabetes surveillance: the views of patients. British Journal of General Practice 42, 279-83.

Murray, S.A. and Paxton, F. 1993: Nurses or doctors: Patient choice in family planning. Health Bulletin 51, 394-98.

NHS Executive. 1999: Patient and public involvement in the new NHS http://www.nhsbeacons.org., retrieved 9 December, 2002.

NHS Executive. 2000: NHS beacons. htttp://www.nhsbeacons. org/, retrieved 9 December, 2000.

Neuberger, J. 1998: Primary care: core values patients' priorities. British Medical Journal 317, 260-62.

O'Reilly, D., Stevenson, M., McCay, C. and Jamison, J. 2001: General practice out of hours service, variations in use and equality in access to a doctor: a cross sectional study. British Journal of General Practice 51, 625-29.
Ovretveit, J., Mathias, P. and Thompson, T. 1997: Interprofessional working for health and social care. Hampshire: Macmillan Press Ltd.

Paxton, F. and Heaney, D. 1997: Minor injuries units: evaluating patients' perceptions. Nursing Standard 12, 45-47.

Paykel, E.S., Mangen, S.P., Griffith, J.H. and Burns, T.P. 1982: Community psychiatric nursing for neurotic patients: a controlled trial. British Journal of Psychiatry 140, 573-81.

Phillips, D. and Brooks, F. 1998: Women users' views on the role and value of the practice nurse. Health and Social Care in the Community 6, 164-71.

Poulton, B. 1995: Keeping the customer satisfied. Primary Health Care 5, 16-19.

Poulton, B.C. 1996: Use of the consultation satisfaction questionnaire to examine patients' satisfaction with general practitioners and community nurses: reliability, replicability and discriminant validity. British Journal of General Practice 46, 26-31.

Priest, R.G., Vize, C., Roberts, A., Roberts, M. and Tylee, A. 1996: Lay people's attitudes to treatment of depression: results of opinion poll for Defeat Depression Campaign just before it's launch. British Medical Journal 313, 858-59.

Pritchard, A. and Kendrick, D. 2001: Practice nurse and health visitor management of acute minor illness in general practice. Journal of Advanced Nursing 36, 556-62.

Rapport, F. and Maggs, C. 1997: Measuring care: the case of district nursing. Journal of Advanced Nursing 25, 673-80.

Ross, F. and Tisser, J. 1997: The care management interface with general practice: a case study. Health and Social Care in the Community 5, 153-61.

Salisbury, C.J. and Tettershall, M.J. 1988: Comparison of the work of a nurse practitioner with that of a general practitioner. Journal of the Royal College of General Practitioners 38, 314-16.

Savage, R. and Armstrong, D. 1990: Effect of a general practitioner's consulting style on patients' satisfaction: a controlled study. British Medical Journal 301, 968-70.

Sergison, M., Sibbald, B. and Rose, S. 1998: Skill mix in primary care - a bibliography. Manchester: National Primary Care Research and Development Centre.

Shum, C., Humphreys, A., Wheeler, D., Cochrane, M. and Clement, S. 2000: Nurse management of patients with minor illnesses in general practice: multicentre, randomized controlled trial. British Medical Journal 320, 1038-43.

Simpson, S., Corney, R., Fitzgerald, P. and Beecham, J. 2000: A randomized controlled trial to evaluate the effectiveness and cost-effectiveness of counselling patients with chronic depression. Health Technology Assessment 4, 36, www.hta. nhsweb.nhs.uk/execsumm/SUMM436.HTM, retrieved 9 December, 2002.

Spiers, R. and Jewell, J.A. 1995: One counsellor, two practices: report of a pilot scheme in Cambridgeshire. British Journal of General Practice 45, 31-33.

Staniszewska, S. and Ahmed, L. 1998: Patient expectations and satisfaction with health care. Nursing Standard 12, 34-38. 
Taylor, G. 2001: Continuity is fine, but not for everything. British Medical Journal 322, 737.

Thorsen, H., Witt, K., Hollanger, H. and Malterud, K. 2001: The purpose of the general practice consultation from the patient's perspective - theoretical aspects. Family Practice 18, 638-43.

Treadway, J. 1983: Patient satisfaction and the content of general practice consultations. Journal of the Royal College of General Practitioners 33, 769-71.

Turton, E.P.L. 2000: Nurse management of patients. British Medical Journal 320, 1038-43.

Venning, P., Durie, A., Roland, M., Roberts, C. and Leese, B.
2000: Randomized controlled trial comparing cost effectiveness of general practitioners and nurse practitioners in primary care. British Medical Journal 320, 1048-53.

Wiles, R. 1997: Empowering practice nurses in the follow-up of patients with established heart disease: lessons from patients' experiences. Journal of Advanced Nursing 26, 729-35.

Williams, B. 1994: Patient satisfaction: a valid concept? Social Science and Medicine 38, 509-16.

Williamson, V. 1995: Personal care and teamwork in primary care: the patient's perspective. Journal of Interprofessional Care 9, $101-106$. 